\title{
PENERAPAN BALANCED SCORECARD SERTA ANALISIS SWOT DALAM PERANCANGAN STRATEGI PADA BADAN USAHA MILIK DAERAH PT BANK X
}

\author{
Kukuh Wahyudi \\ Universitas Airlangga \\ wahyudi.kukuh@gmail.com \\ Nimas Aryany Pratiwi \\ Universitas Airlangga \\ nimashalim@yahoo.com \\ Maria Eliza \\ Universitas Airlangga \\ mria.eliza@gmail.com
}

\begin{abstract}
The Balanced Scorecard analyzes the overall performance of the organization through four perspectives. This study tries to show a Balance Scorecard perspective, then a SWOT analysis and can determine the company's position according to the Internal External Matrix. The object of this research is a holding company in the banking sector. Data collection methods in this study are primary and secondary data. Primary data can be obtained through interviews with key informants, and secondary data is obtained through documentation of the required data obtained from PT Bank X. The matrix is in accordance with the company's SWOT, then the results will be clarified using the IFE Matrix (Strength - Weakness) and EFE Matrix (Opportunities - Threats). The two Matrix that have been formed are plotted into the Internal - External Matrix and are in quadrant I, so that PT Bank X's strategic position can be found in the Grow and Build position. The most appropriate strategy based on the Grow and Build position is to apply an Intensive Strategy with a specific strategy using market development strategies and product development. Based on the analysis of the BSC and IE Matrix, a strategic recommendation is produced on product development, including making efforts to improve the quality of human resources, improve credit quality, and digitize banking in preparing for competition in the era of industrial revolution 4.0.
\end{abstract}

Keywords: balance scorecard; banking and finance; internal and external matrix; sustainable development growth; SWOT analysis.

\section{PENDAHULUAN}

Pada umumnya organisasi memiliki tujuan dalam menjalankan aktivitasnya yaitu sustainable development growth dan ekspansi usaha. Untuk mencapai tujuan tersebut, perusahaan harus memiliki competitive advantage sehingga dapat bertahan dalam menghadapi persaingan. Dibutuhkan suatu sistem pengukuran yang komprehensif dalam mengukur competitive advantage agar dapat mengikuti perkembangan industri perbankan. Secara tradisional, pengukuran terhadap bisnis berkisar pada pengukuran financial perspective. Namun, pengukuran kinerja yang hanya memertimbangkan financial perspective akan membuat penilaian menjadi tidak seimbang. Dalam hal ini, balanced scorecard membantu organisasi untuk mengukur kinerja organisasi secara efektif dan menerapkan strategi dengan sukses (Talebnia, 2012).

Dalam membuat Balance scorecard (BSC), pihak manajemen perusahaan harus menentukan faktorfaktor apa saja yang menjadi penentu kesuksesan (Critical Success Factors) dari perusahaan. Terdapat dua faktor, yaitu internal dan eksternal. Faktor internal merupakan faktor yang berasal dari dalam perusahaan, sedangkan faktor eksternal merupakan faktor yang berasal dari luar perusahaan. Untuk menganalisa faktor-faktor tersebut, manajemen perusahaan dapat menggunakan analisis, untuk mengetahui kekuatan (strength), kelemahan (weakness), peluang (opportunity) dan ancaman (threat) sebagai basic elements yang dapat memengaruhi keberhasilan perusahaan (Srivastava et al., 2013), serta Key Performance Indicator sebagai ukuran keuangan dan non-keuangan yang digunakan organisasi untuk mengungkapkan seberapa sukses dalam mencapai tujuan jangka panjang (Velimirovi et al., 2011). 
Kukuh Wahyudi, Nimas Aryany Pratiwi, \& Maria Eliza. Penerapan Balanced Scorecard serta Analisis SWOT dalam Perancangan Strategi pada Badan Usaha Milik Daerah PT Bank X

Informasi strategis yang diidentifikasi berdasarkan critical success factors, menjadi peta bagi perusahaan untuk menunjukkan jalan ke arah keberhasilan secara kompetitif. Ukuran-ukuran keuangan seperti profitabilitas merupakan sebuah pengukuran jangka pendek. Tanpa informasi strategis tersebut, perusahaan akan sering tersesat dalam perjalanannya menuju keberhasilan kompetitif dan sering salah dalam mengambil keputusan; misalnya metode pemasaran dan distribusi yang salah (Febrina, 2012).

Strategi yang diterapkan harus tepat dan sesuai dengan kondisi perusahaan. Strategi yang tepat akan mampu membawa perusahaan ke dalam keberhasilan kompetitif. Untuk mendukung hal tersebut manajemen perusahaan harus berpikir apakah memang benar strategi yang telah diterapkan telah sesuai dengan kondisi internal dan eksternal perusahaan. Berkaitan dengan pentingnya proses penerapan strategi yang tepat oleh manajemen, objek penelitian ini adalah perusahaan yang bergerak di sektor perbankan yaitu PT. Bank X yang merupakan badan usaha milik daerah pemerintah propinsi. Menurut data tahunan PT Bank X pada Tabel 1, sebagai perusahaan jasa keuangan badan usaha milik daerah, penyaluran kredit tumbuh signifikan untuk segmen konsumer dengan peningkatan sekitar $6,5 \%$ selama periode tahun 2017 hingga 2019.

\section{Tabel 1.
BUSINESS PERFORMANCE HIGHLIGHT PT BANK X TAHUN 2019}

\begin{tabular}{lccc}
\multicolumn{1}{c}{ Jenis Segmen dan Ukuran Kinerja } & $\mathbf{2 0 1 7}$ & $\mathbf{2 0 1 8}$ & $\mathbf{2 0 1 9}$ \\
\hline Segmen Menengah, Korporasi dan Sindikasi/ Medium & & & \\
Penyaluran Kredit & $6,3 \mathrm{~T}$ & $6,9 \mathrm{~T}$ & $8,7 \mathrm{~T}$ \\
Debitur & 7.514 & 7.215 & 6.210 \\
Segmen Produktif & & & \\
Penyaluran Kredit & $2,7 \mathrm{~T}$ & $2,9 \mathrm{~T}$ & $3,5 \mathrm{~T}$ \\
Debitur & 40.384 & 44.021 & 47.021 \\
Segmen Konsumen & & & \\
Penyaluran Kredit & $21,7 \mathrm{~T}$ & $22,9 \mathrm{~T}$ & $24,6 \mathrm{~T}$ \\
Debitur & 239.548 & 236.322 & 234.504 \\
\hline
\end{tabular}

Sumber: Annual Report PT Bank X $(2017,2018,2019)$

Berdasarkan tabel 1, pertumbuhan yang sama juga terjadi pada segmen konsumer menengah, korporasi serta kredit sindikasi dengan prosentase peningkatan rata-rata sebesar 17,8\%. Namun terdapat penurunan jumlah debitur pada masing-masing segmen tersebut, di mana rata-rata penurunan debitur pada kredit segmen UKM, menengah dan sindikasi adalah sebesar 9\%, serta rata-rata penurunan debitur pada kredit segmen konsumer sebesar 1,05\% dalam kurun waktu tahun 2017 hingga 2019.

Dalam menghadapi hal ini, PT Bank X berupaya untuk memastikan business performance dalam mendukung pencapaian target perusahaan, manajemen perusahaan harus memastikan bahwa strategi tersebut telah benar-benar mampu membawa perusahaan ke arah keberhasilan. Strategi yang diterapkan tidak hanya untuk menghadapi ancaman persaingan saja, namun adanya regulasi perbankan yang semakin ketat juga dapat mengancam keberadaan perusahaan. Melalui beberapa alasan tersebut, penelitian ini menganalisis kinerja bank menggunakan metode BSC dengan implementasi key performane indikator serta analisis SWOT dan penentuan posisi strategis sesuai Internal External Matrix sebagai alat bantu. Dengan tujuan perusahaan mampu bersaing dengan perusahaan lain serta mampu memertahankan keberlangsungan hidup perusahaan.

Terdapat beberapa metode yang digunakan dalam pengembangan strategi untuk meningkatkan kemampuan atau kapabilitas. Rostami et al. (2015) menggunakan balance scorecard model sebagai sistem evaluasi pada Bank dan measurement systems yang dalam penyusunan rencana jangka pendek maupun jangka panjang, serta sebagai sistem pengendali internal maupun eksternal. Rafiq et al. (2020) meneliti pengaruh empiris dari sistem manajemen strategis pada sustainable development dengan menggunakan balanced scorecard, sebagai teoritis, dan organizational performance, sebagai variabel intervening. Ika et al. (2012) mengeksplorasi project success factor pada World Bank, serta secara 
spesifik menganalisa hubungan antara critical success factor dan keberhasilan proyek yang dialami oleh World Bank Task Team sebagai project supervisors. Faktor eksplorasi menitikberatkan lima poin critical success factors, di antaranya monitoring, coordination, design, training serta lingkungan institusi. Wu (2012) menggunakan metodologi evaluasi struktural untuk menghubungkan key performance indicators ke dalam strategi balanced scorecard pada industri perbankan.

Penelitian ini bertujuan menganalis posisi Badan Usaha Milik Daerah dengan kuadran internal external matrix SWOT. Penelitian ini terdiri dari beberapa bagian. Bagian pertama membahas latar belakang. Bagian dua membahas tentang studi literatur terkait dengan teori analisa SWOT, balance scorecard, serta Internal-External Matrix. Bagian tiga membahas tentang metode penelitian, kerangka penelitian, desain penelitian dan metode yang digunakan. Bagian empat menjelaskan tentang analisis hasil dengan penjabaran melalui balance scorecard, analisa SWOT sebagai dasar untuk mengetahui posisi PT Bank $\mathrm{X}$ pada kuadran internal external matrix. Bagian kelima menjelaskan tentang kesimpulan dalam penelitian.

\section{KAJIAN PUSTAKA}

\section{Analisis SWOT (Strength, Weakness, Opportunity, dan Threat)}

Analisis SWOT adalah teknik yang paling umum yang bisa digunakan untuk menganalisis kasus strategis, yang digunakan untuk perencanaan dan manajemen strategis dalam organisasi. Hal ini dapat digunakan secara efektif untuk membangun strategi organisasi dan strategi bersaing (Gurel, 2017). SWOT adalah alat yang sering digunakan untuk menganalisis lingkungan internal dan eksternal untuk mencapai pendekatan dan dukungan sistematis untuk situasi keputusan. SWOT adalah akronim Strength (S), Weakness (W), Opportunity (O), dan Threat (T). Dua faktor pertama (kekuatan dan kelemahan) terkait dengan faktor internal organisasi, sementara peluang dan ancaman mencakup konteks atau lingkungan yang lebih luas di mana organisasi beroperasi (Namugenyi et al., 2019). Beneda (2008) menjelaskan bahwa untuk memertahankan posisi kompetitif organisasi sebagai key factor bagi stockholder wealth preservation menyarankan organisasi untuk melakukan analisis kompetitif, di mana SWOT adalah bagian penting untuk meninjau kompetitor. Sesuai Lampiran 1, diagram alur SWOT oleh Ritson (2008), faktor internal dan eksternal disebut sebagai faktor strategis, dan dirangkum dalam analisis SWOT. Kekuatan dan kelemahan merupakan faktor dalam sistem yang memungkinkan dan menghalangi organisasi mencapai tujuannya. Peluang dan ancaman dianggap sebagai faktor eksternal yang memfasilitasi dan membatasi organisasi dalam mencapai tujuannya masing-masing.

\section{Balanced Scorecard (BSC)}

Balanced scorecard adalah metode yang efisien untuk manajer dalam mengamati laporan dan analisis menggunakan key performance indicator, untuk menentukan apakah kegiatan operasional sejalan dengan strategi dan visi global entitas (Bostan \& Grosu, 2011). Menurut Kairu et al. (2013), BSC adalah cara untuk mengukur keberhasilan organisasi, unit bisnis atau departemen; menyeimbangkan tindakan jangka panjang dan jangka pendek; melalui perspektifnya serta mengikat strategi perusahaan dengan ukuran tindakan. Perusahaan menggunakan balanced scorecard untuk mengelola proses manajemen, seperti pada Gambar 1: klarifikasi dan penterjemahan misi, visi dan strategi; komunikasi dan menghubungkan sasaran dan ukuran objektif; rencana, penetapan target, dan penyelarasan inisiatif strategi; serta peningkatan umpan balik strategi dan pengetahuan.

Tujuan dengan penggunaan balanced scorecard dalam perusahaan sebagai kerangka sistem manajemen adalah sebagai berikut. (1) Menciptakan nilai bagi para pemegang saham dengan manajemen keuangan yang tepat guna. (2) Menciptakan nilai bagi pelanggan melalui strategi pemasaran yang responsif terhadap kebutuhan dan harapan pelanggan. (3) Menciptakan nilai bagi masa depan, melalui penciptaan iklim kerja yang kondusif; (4) Bekerja secara efisien dan efektif dengan mengacu pada proses bisnis yang memungkinkan kerjasama yang sinergis (Kairu et al., 2013). 
Kukuh Wahyudi, Nimas Aryany Pratiwi, \& Maria Eliza. Penerapan Balanced Scorecard serta Analisis SWOT dalam Perancangan Strategi pada Badan Usaha Milik Daerah PT Bank X

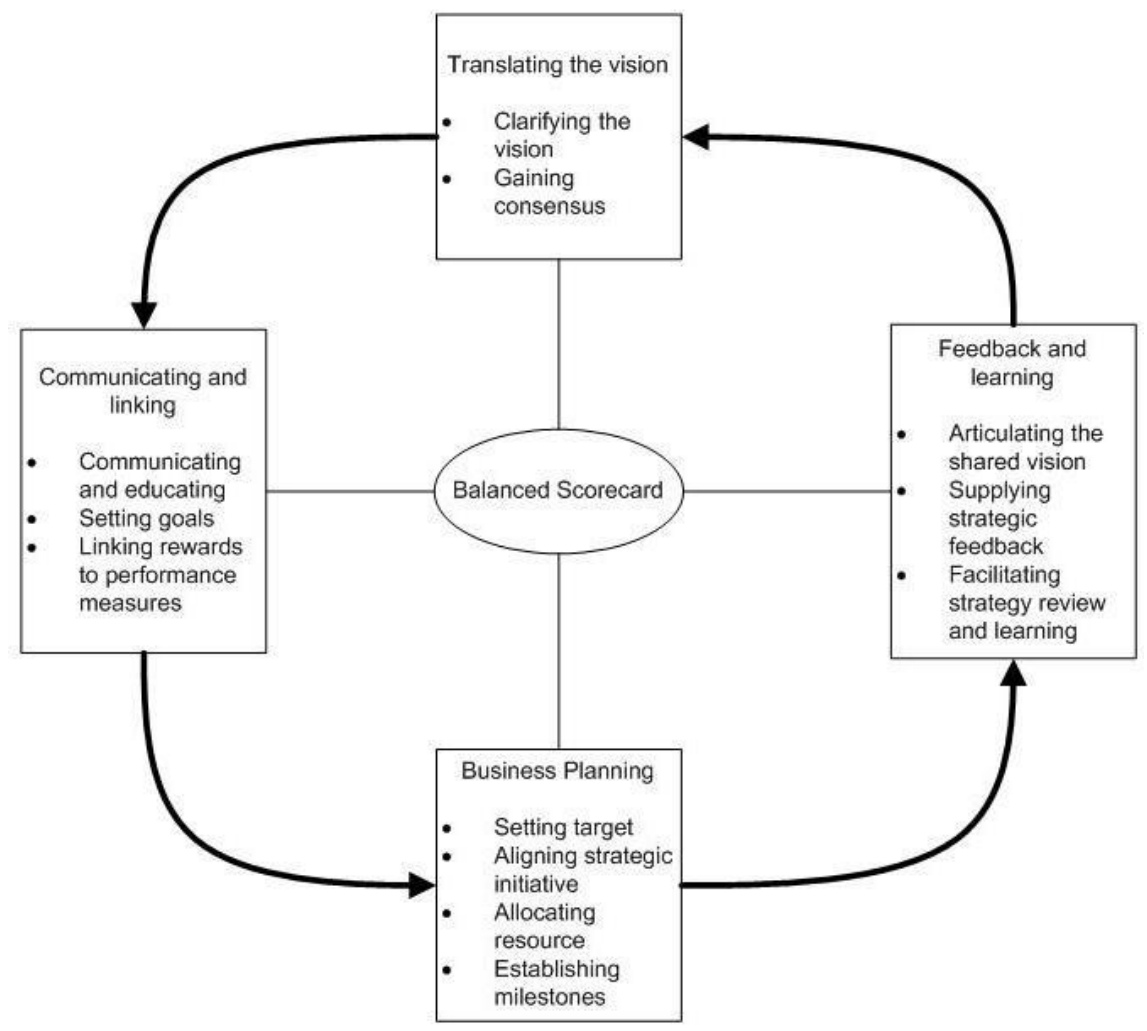

Sumber: Kaplan \& Norton (1996)

\section{Gambar 1. BALANCED SCORECARD DALAM KERANGKA MANAJEMEN STRATEGI}

Dapat dikatakan bahwa balanced scorecard merupakan salah satu teknik pengukuran yang penting karena kemampuannya untuk memasukkan variabel keuangan dan non keuangan dalam mengukur kinerja organisasi. Balanced scorecard dibagi menjad empat perspektif berbeda yang meliputi finance, customer, internal business process, dan perspektif learning \& growth (Kaplan \& Norton, 1992).

Internal business process dipantau untuk memastikan bahwa kinerja akan selalu memuaskan. Perspektif proses internal melaporkan efisiensi proses dan prosedur internal. Najjar \& Kalaf (2012) berpandangan bahwa proses bisnis internal menyediakan organisasi dengan sarana sesuai harapan kinerja dapat dicapai. Menurut Kairu et al. (2013), perspektif proses internal berfokus pada hasil bisnis internal yang mengarah pada kesuksesan finansial dan pelanggan yang puas. Untuk memenuhi tujuan organisasi dan harapan pelanggan, organisasi harus mengidentifikasi proses bisnis utama di mana mereka harus unggul. Perspektif proses internal melaporkan efisiensi proses dan prosedur internal. Najjar \& Kalaf (2012) berpandangan bahwa proses bisnis internal menyediakan organisasi dengan sarana yang harapan kinerja dapat dicapai.

Perspektif customer menangkap kemampuan organisasi untuk menyediakan barang dan jasa yang berkualitas, efektivitas penyampaiannya, dan layanan dan kepuasan pelanggan secara keseluruhan. Ini akan dihasilkan dari harga, kualitas, ketersediaan, pemilihan, fungsionalitas, layanan, kemitraan, dan proposisi nilai merek, yang akan mengarah pada peningkatan akuisisi dan retensi pelanggan (Kairu et al., 2013). BSC menuntut manajer menerjemahkan pernyataan misi umum mereka pada layanan pelanggan ke dalam ukuran khusus yang mencerminkan faktor-faktor yang benar-benar penting bagi pelanggan (Kaplan \& Norton, 1992). Kekhawatiran pelanggan cenderung jatuh ke dalam empat kategori: waktu, kualitas, kinerja dan layanan, dan biaya. Menurut Najjar \& Kalaf (2012), ukuran keuangan menyampaikan konsekuensi ekonomi atas tindakan yang telah diambil oleh organisasi, dan fokus pada ukuran terkait profitabilitas di mana pemegang saham memverifikasi profitabilitas investasi.

Perspektif learning \& growth melihat bagaimana seorang karyawan suatu organisasi belajar dan berkembang dalam karirnya untuk meningkatkan kinerja organisasi. Menurut Kairu et al. (2013) 
perspektif pembelajaran dan pertumbuhan meneliti kemampuan karyawan (keterampilan, bakat, pengetahuan dan pelatihan), kualitas sistem informasi (sistem, database, dan jaringan) dan efek keselarasan organisasi (budaya, kepemimpinan, keselarasan dan kerja tim), dalam mendukung pencapaian tujuan organisasi'. Proses hanya akan berhasil jika karyawan yang cukup terampil dan termotivasi, dilengkapi dengan informasi yang akurat dan tepat waktu dan dipimpin oleh kepemimpinan yang efektif, mendorong mereka. Mereka akan mengarah pada produksi dan pengiriman produk dan layanan berkualitas; dan akhirnya kinerja keuangan yang sukses (Gekonge, 2005).

\section{METODE PENELITIAN}

Objek pada penelitian ini adalah perusahan sektor perbankan, yakni PT Bank X. Metode pengumpulan data pada penelitian ini adalah dengan data primer dan sekunder. Data primer diperoleh melalui wawancara dengan 3 kepala divisi sebagai key informan, serta data sekunder didapat melalui dokumentasi data-data yang didapat melalui laporan keuangan perusahaan periode 2017, 2018 dan 2019.

Analisis menggunakan integrasi model BSC dan Internal External Matrix. Model BSC pada Perspektif keuangan menggunakan indikator return on assets (ROA), return on equity (ROE), rasio efisiensi, loan to deposit ratio dan non performing loan (Svitalkova, 2014). Perspektif pelanggan menggunakan tingkat pemerolehan nasabah, tingkat retensi nasabah, dan tingkat profitabilitas nasabah (Olson \& Slater, 2002). perspektif proses bisnis internal menggunakan indikator: network growth ratio dan administrative expense to total revenue (Tuan, 2020). Perspektif proses pertumbuhan dan pembalajaran menggunakan indikator: retensi karyawan, produktivitas karyawan, serta pelatihan karyawan (Olson \& Slater, 2002).

Tahap berikutnya adalah melakukan analisa terhadap faktor-faktor lingkungan eksternal dan internal yang telah diidentifikasi dan dikategorikan sebelumnya. Dalam melakukan analisis permasalahan dipakai metode analisis The Internal Factor Evaluation (IFE) Matrix dan The External Factor Evaluation (EFE) Matrix dengan menggunakan Internal-External (IE) Matrix untuk menentukan posisi strategik perusahaan dan menentukan strategi yang tepat untuk dikembangkan.

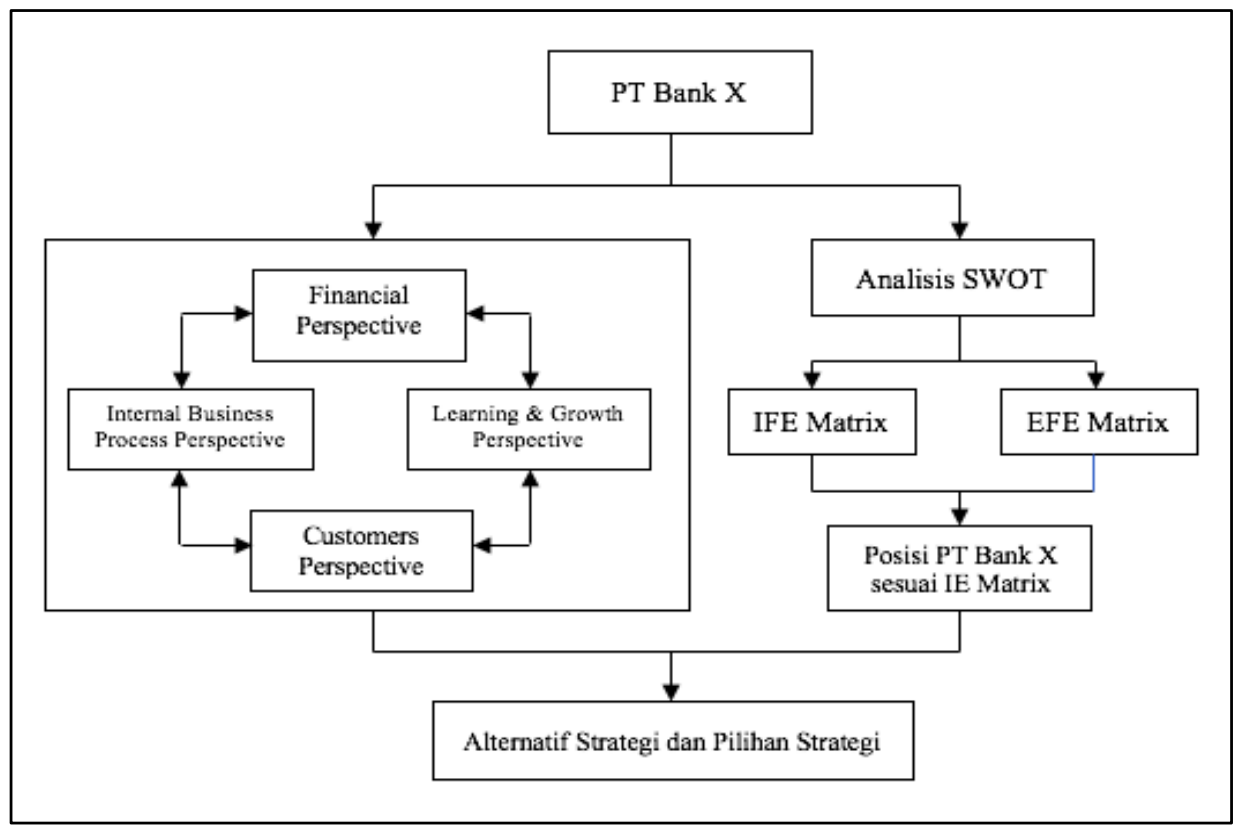

Gambar 2. KERANGKA KONSEPTUAL

\section{HASIL DAN PEMBAHASAN}


Kukuh Wahyudi, Nimas Aryany Pratiwi, \& Maria Eliza. Penerapan Balanced Scorecard serta Analisis SWOT dalam Perancangan Strategi pada Badan Usaha Milik Daerah PT Bank X

Penjabaran Menggunakan Balance Scorecard (BSC)

Hasil analisis data keempat perspektif pada Balance Scorecard memiliki keterkaitan antar satu dengan lainnya. Penilaian kinerja dengan menggunakan 4 (empat) perspektif Balanced Scorecard pada tabel 2.

Tabel 2.

BALANCE SCORECARD PT BANK X

\begin{tabular}{lcccc}
\hline \multicolumn{1}{c}{ Keterangan } & $\mathbf{2 0 1 7}$ & $\begin{array}{c}\text { Tahun } \\
\mathbf{2 0 1 8}\end{array}$ & $\mathbf{2 0 1 9}$ & $\begin{array}{c}\text { Rata -rata } \\
\text { (\%) }\end{array}$ \\
\hline Perspektif Keuangan & & & & \\
Return on Assets & $3,12 \%$ & $2,96 \%$ & $2 \%$ & $3 \%$ \\
Return On Equity & $17,43 \%$ & $17,75 \%$ & $18 \%$ & $18 \%$ \\
Rasio Efisiensi & $68,63 \%$ & $69,45 \%$ & $71,40 \%$ & $70 \%$ \\
$\begin{array}{l}\text { Loan to Deposit Ratio } \\
\text { Non-Performing Loan }\end{array}$ & $79,69 \%$ & $66,57 \%$ & $63 \%$ & $70 \%$ \\
$\begin{array}{l}\text { Perspektif Proses Bisnis Internal } \\
\text { Network Growth Ratio }\end{array}$ & $4,59 \%$ & $3,75 \%$ & $2,77 \%$ & $4 \%$ \\
Administrative Expense to Total Revenue & $3 \%$ & $5 \%$ & $3 \%$ & $4 \%$ \\
Perspektif Pelanggan & $29 \%$ & $29 \%$ & $32 \%$ & $30 \%$ \\
Tingkat Pemerolehan Nasabah & & & & \\
Tingkat Retensi Nasabah & $10 \%$ & $10 \%$ & $8 \%$ & $9 \%$ \\
Tingkat Profitabilitas Nasabah & $90 \%$ & $90 \%$ & $92 \%$ & $91 \%$ \\
Perspektif Pertumbuhan Dan Pembelajaran & $43 \%$ & $42 \%$ & $40 \%$ & $42 \%$ \\
Retensi karyawan & & & & \\
Produktivitas karyawan & $0,13 \%$ & $0,13 \%$ & $0,20 \%$ & $0,15 \%$ \\
Pelatihan karyawan & 410,7 & 379,09 & 359,32 & 383,036667 \\
\hline
\end{tabular}

Sumber: Data diolah (2021)

\section{Perspektif Keuangan}

Hasil penelitian ini menunjukkan bahwa perusahaan dari tahun 2017 hingga 2019 dapat mencapai cost effectiveness, meskipun rasio BOPO meningkat selama 3 tahun berturut - turut dan meningkatkan pertumbuhan laba bersih sebesar $4-5 \%$. Hasil rasio keuangan yang telah diukur meliputi hasil nilai rata-rata pada beberapa rasio, diantaranya ROA sebesar 3\% (sehat), ROE sebesar 18\% (sehat), Rasio efisiensi (BOPO) sebesar 70\% (sehat), LDR sebesar 70\% (sangat sehat), NPL sebesar 12\% (kurang sehat). Kinerja pada perspektif keuangan menunjukkan hasil yang cukup baik bahkan terus mengalami perkembangan yang baik.

\section{Perspektif Proses Bisnis Internal}

Pada proses bisnis internal rata-rata keseluruhan Network Growth Ratio adalah sebesar $4 \%$ dan prosentase rata-rata AETR sebesar $30 \%$. Penilaian ini bertujuan untuk pengembangan inovasi dengan cara memperluas struktur jaringan operasional, desain produk perbankan, efisiensi, efektivitas serta ketepatan waktu proses atas transaksi yang dilakukan untuk meningkatkan layanan. Hal tersebut berpengaruh pada perspektif nasabah/ konsumen yang dapat mencapai rata-rata profitabilitas nasabah sebesar $42 \%$ serta perolehan prosentase nasabah sebesar 9\% serta pada tingkat mempertahankan nasabah sebesar $91 \%$ yang mengidentifikasi hasil tersebut termasuk dalam kategori cukup baik.

\section{Perspektif Nasabah}

Hasil dari penelitian ini menunjukkan bahwa perusahaan tetap mempertahankan daya saing, suku bunga, meningkatkan penguasaan segmen pasar guna memenuhi kebutuhan nasabahnya. Selain itu, dapat dilihat juga nilai rata-rata yang diperoleh dari profitabilitas nasabah yang menyentuh angka sebesar $42 \%$. Hal ini menandakan semakin tinggi profitabilitas maka semakin tinggi perolehan laba yang berhasil diraih oleh perusahaan

\section{Perspektif Pertumbuhan dan Pembelajaran}


Kinerja perspektif pertumbuhan dan pembelajaran perusahaan mengalami penurunan selama periode tahun 2017 hingga tahun 2019, dengan rata-rata sebesar $62 \%$ lebih rendah $1 \%$ jika dibandingkan dengan prosentase pelatihan karyawan pada tahun 2017 , hal ini memengaruhi tingkat produktivitas karyawan yang juga mengalami penurunan selama periode tiga tahun berjalan. Namun, prosentase retensi karyawan meningkat pada tahun 2019. Hasil menunjukkan peningkatan yang mengindikasikan bahwa produktivitas karyawan mengalami up and down dalam perolehan hasil prosentase disetiap tahunnya. Produktivitas karyawan mengalami penurunan setiap tahunnya sekitar 5-8\%, hal ini juga memicu terjadinya kenaikan pada retensi karyawan, terutama pada tahun berjalan 2018 hingga 2019. Perusahaan juga mengalami penurunan prosentase pada pelatihan karyawan.

\section{Analisis SWOT}

Berdasarkan analisis terhadap faktor eksternal maupun internal, dapat diidentifikasi faktor Strengths, Weaknesses, Opportunities dan Threats yang dimiliki PT Bank X, pada Lampiran 1. Berdasarkan identifikasi faktor internal eksternal menggunakan analisis SWOT, selanjutnya dilakukan evaluasi melalui wawancara dengan 3 kepala divisi sebagai key informan untuk mengetahui bobot dan peringkat masing-masing faktor menggunakan External Factor Evaluation (EFE Matrix) dan Internal Factor Evaluation (IFE Matrix), kemudian dicocokkan menggunakan Internal External Matrix yang digunakan dalam analisis strategis karena memberikan pemahaman yang lebih mendalam untuk evaluasi posisi kompetitif organisasi dibandingkan dengan para pesaingnya. (Cassidy et al., 2013)

\section{External Factor Evaluation Matrix dan Internal Factor Evaluation Matrix}

Tabel 3.

\section{EXTERNAL AND INTERNAL FACTOR EVALUATION MATRIX}

\begin{tabular}{|c|c|c|c|}
\hline Faktor Eksternal dan Faktor Internal & Bobot & Peringkat & $\begin{array}{l}\text { Nilai yang } \\
\text { dibobotkan }\end{array}$ \\
\hline \multicolumn{4}{|l|}{ Opportunities } \\
\hline Akses ke daerah terpencil propinsi untuk ekspansi & 0,18 & 3 & 0,54 \\
\hline Relasi yang baik dengan pemerintah daerah & 0,16 & 4 & 0,64 \\
\hline Terbiasa menangani kelompok usaha skala kecil & 0,13 & 3 & 0,39 \\
\hline Suku bunga SBI diperkirakan akan tetap tinggi & 0,105 & 4 & 0,42 \\
\hline Meningkatnya penggunaan Internet of Things & 0,12 & 4 & 0,48 \\
\hline \multicolumn{4}{|l|}{ Threats } \\
\hline Produk perbankan pesaing relatif inovatif dan menarik & 0,13 & 2 & 0,26 \\
\hline Tingkat persaingan di industri jasa keungan kian meningkat & 0,075 & 1 & 0,075 \\
\hline Financial technology berkembang cukup pesat & 0,1 & 2 & 0,2 \\
\hline Jumlah & 1 & & 3,005 \\
\hline \multicolumn{4}{|l|}{ Strengths } \\
\hline $\begin{array}{l}\text { Rasio keuangan yang cukup sehat sesuai kriteria Bank } \\
\text { Indonesia }\end{array}$ & 0,16 & 3 & 0,48 \\
\hline Jaringan pelayanan yang cukup luas pada propinsi tersebut & 0,203 & 4 & 0,812 \\
\hline $\begin{array}{l}\text { Sumber dana yang dikelola relatif murah, didominasi oleh } \\
\text { pemerintah }\end{array}$ & 0,15 & 4 & 0,6 \\
\hline Retensi karyawan sangat kecil & 0,09 & 3 & 0,27 \\
\hline $\begin{array}{l}\text { Hubungan kelembagaan yang baik termasuk lembaga } \\
\text { pemerintah dan swasta }\end{array}$ & 0,1 & 4 & 0,4 \\
\hline \multicolumn{4}{|l|}{ Weakness } \\
\hline Product development kurang inovatif & 0,09 & 2 & 0,18 \\
\hline Aktivitas pemasaran relatif kurang agresif & 0,06 & 2 & 0,12 \\
\hline Corporate image masih sangat kental sebagai bank daerah & 0,08 & 1 & 0,08 \\
\hline Teknologi sistem informasi perlu disempurnakan & 0,067 & 2 & 0,134 \\
\hline Jumlah & 1 & & 3,076 \\
\hline
\end{tabular}

Sumber: Hasil wawancara (2021, data diolah) 
Kukuh Wahyudi, Nimas Aryany Pratiwi, \& Maria Eliza. Penerapan Balanced Scorecard serta Analisis SWOT dalam Perancangan Strategi pada Badan Usaha Milik Daerah PT Bank X

Setelah melakukan perhitungan dengan menggunakan metode Internal Factor Evaluation (IFE) dan External Factor Evaluation (EFE), maka dapat diketahui posisi strategik PT Bank X di Internal External (IE) Matrix dan selanjutnya dapat digunakan sebagai dasar dalam menentukan strategi bisnis yang paling mungkin diterapkan pada PT Bank X.

Diketahui faktor-faktor eksternal PT Bank X memiliki total score tertimbang 3,005 dan faktor-faktor internal PT Bank X memiliki total score tertimbang 3,076. Hasil analisa melalui metode EFE-IFE Matrix apabila dimasukkan ke dalam Internal External Matrix, berada di kuadran I, sehingga dapat diketahui posisi strategik PT Bank X pada posisi Grow and Build. Grow and Build strategy didesain untuk mencapai pertumbuhan, dari segi penjualan, assets, profit maupun kombinasi ketiganya. Hal ini dapat dilakukan melalui upaya peluang pertumbuhan: intensif, integratif, diversifikasi. Pertumbuhan intensif menyangkut peluang dalam produk perusahaan dan cakupan aktivitas pasar, umumnya akan memasukkan kategori penetrasi pasar, pengembangan pasar, dan pengembangan produk. Pertumbuhan integratif menyangkut peluang di bagian lain dari inti sistem pemasaran. Pertumbuhan diversifikasi menyangkut peluang di luar sistem pemasaran inti. (Varadarajan \& Berry, 1983).

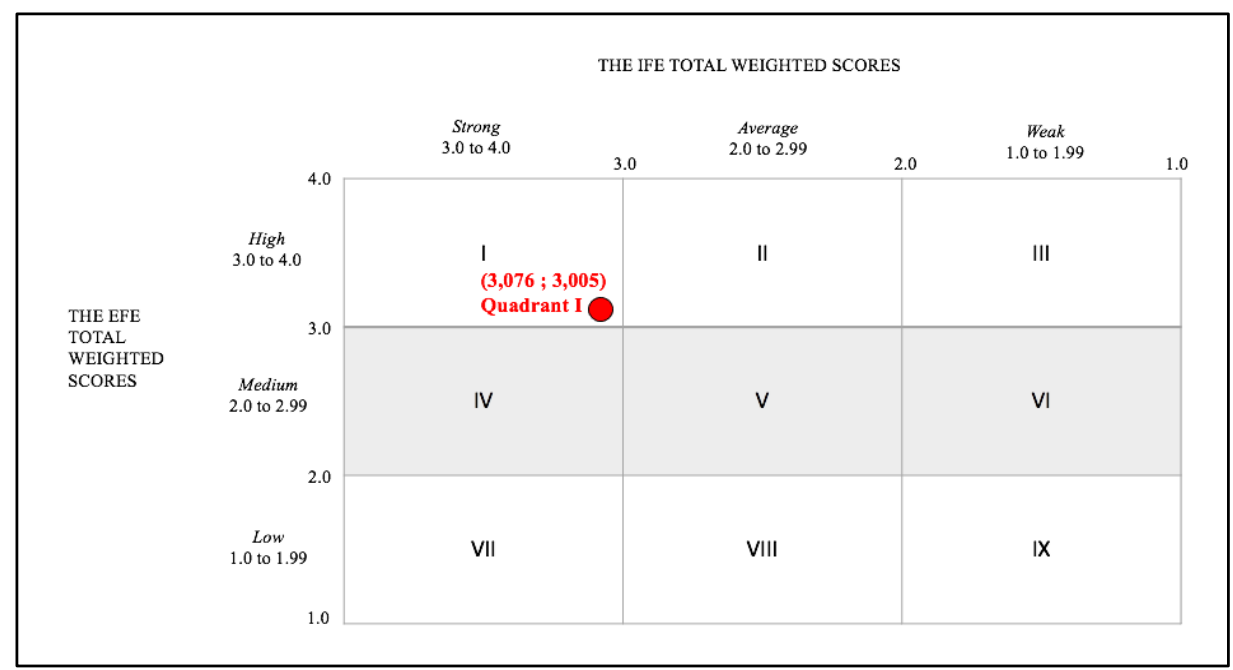

Sumber: Data diolah (2021)

Gambar 3. IE MATRIX PT BANK X

Strategi pertumbuhan terbuka yang tepat adalah product development yang melibatkan pengembangan layanan atau produk baru untuk pasar. Perusahaan dapat memperluas jaringan operasional dengan cara memperluas jaringan kantor, pengembangan berbagai produk dan jasa yang ditawarkan. Hal ini bertujuan untuk meningkatkan layanan purna jual dan memberikan tambahan manfaat kepada para nasabah agar tetap mempunyai loyalitas terhadap perusahaan. Strategi product development pada PT Bank X secara spesifik adalah melalui peningkatan kualitas SDM, perbaikan layanan kredit, serta digitalisasi perbankan dalam mempersiapkan persaingan di era revolusi industri 4.0.

\section{Perbaikan Kualitas Kredit}

Keberhasilan usaha bank di ukur dari kelancaran pengembalian kredit yang dicerminkan oleh rendahnya tingkat Non Performing Loan (NPL) yang mencerminkan kualitas kredit dari portofolio kredit bank. (Ozili, 2019). Sehingga perlu adanya kerja keras dari pengurus kredit untuk meminimalkan NonPerforming Loan. Sesuai dengan penelitian sebelumnya, meminimalkan non performing loan atau kredit bermasalah adalah kondisi yang diperlukan untuk meningkatkan pertumbuhan ekonomi (Messai \& Jouini, 2013).

Upaya menjaga kualitas kredit dapat dilakukan dengan mengoptimalkan sejumlah strategi, dimulai dari ketentuan persetujuan plafond kredit. Keputusan plafon kredit tertuang dalam peraturan otoritas jasa keuangan nomor 42/POJK.03/2017 tentang kewajiban penyusunan dan pelaksanaan kebijakan perkreditan atau pembiayaan bank bagi bank umum. Pemberian kredit untuk seluruh segmen hanya di 
tujukan kepada nasabah yang berkualitas dengan pemberian yang prudent sesuai dengan aturan otoritas dan kebijakan internal.

Kemudian PT Bank X dapat menelaah mitigasi risiko yang lebih prudent serta langkah restrukturisasi kredit bermasalah. Seringkali kredit bermasalah timbul dari berbagai faktor antara lain: (1) usaha debitur/ nasabah mengalami penurunan baik dari kondisi persaingan dilingkungan sampai pada kondisi cuaca; (2) terjadinya musibah kecelakaan dan sakit sehingga uang yang seharusnya untuk pembayaran angsuran digunakan untuk melakukan pengobatan; (3) perbaikan rumah akibat suatu bencana; (4) perbaikan armada transportasi yang digunakan debitur.

Sementara itu, dalam upaya mengatasi kredit bermasalah diharapkan PT bank X tetap konsisten untuk langkah-langkah yang diambil sebagai kunci kesiapan perbankan dalam menghadapi kredit bermasalah kedepannya agar dengan mudah dalam menyelesaikan ketika terjadi kredit yang tidak diharapkan.

Tindakan yang paling mendasar dilakukan oleh bank adalah dengan penagihan intensif. Apabila tidak ada perbaikan dalam hal pembayaran angsuran kredit, pihak bank memberikan surat peringatan pertama, dan (biasanya) hingga surat peringatan ketiga. Jika upaya penagihan intensif tidak mampu untuk mengembalikan kredit bermasalah menjadi lancar maka upaya yang dilakukan dapat berupa restrukturisasi. Jika upaya restrukturisasi masih mengalami kegagalan maka bank memiliki langkah dengan menjual agunan/ jaminan. Agunan/jaminan yang diberikan nasabah kepada bank menjadi sumber kekuatan dalam melakukan upaya penyelesaian

\section{Digitalisasi Perbankan dalam Mempersiapkan Persaingan di Era Revolusi Industri 4.0}

Salah satu faktor baru yang secara signifikan memertahankan keunggulan kompetitif adalah infrastruktur teknologi informasi perusahaan dalam layanan tanpa batas untuk customer. (liang et al., 2010). Era digital banking 4.0 menjadi peluang bagi perbankan untuk lebih berinovasi memberikan layanan kepada nasabah. Inovasi tersebut dibutuhkan untuk menyikapi persaingan seiring pesatnya pertumbuhan financial technology (fintech). Perbankan akan terpengaruh dengan disrupsi dari era digital teknologi dalam revolusi industri 4.0 jika tidak menyikapi secara tepat dan cepat. Hal ini disebabkan perilaku konsumen berubah menuntut perbankan untuk lebih adaptif dengan teknologi digital. Teknologi digital sebagai peluang untuk meningkatkan performance perbankan secara keseluruhan, membuka kompetisi, kedatangan fintech juga membuka persaingan

Selaku regulator, OJK berupaya untuk membuat aturan yang mampu mengikuti perkembangan zaman. Untuk itu, OJK telah menyusun Peraturan OJK (POJK) Nomor 12/2018 yang salah satunya bertujuan untuk mendukung efisiensi operasional, meningkatkan layanan, dan mengadopsi teknologi TI. Dengan regulasi tersebut perbankan bisa menyikapi disruption karena dari sisi regulasi sudah cukup mendukung. Dengan kata lain, layanan perbankan sudah bisa dalam genggaman tangan.

PT Bank X dapat membentuk Sub Divisi Pengembangan Digital Banking untuk merumuskan pengembangan produk dan layanan digital Bank serta IT Strategic Plan dengan menyertakan Key Performance Indicator (KPI) sebagai indikator keberhasilan, contoh idnikator tersebut antara lain adalah: memenuhi kebutuhan layanan teknologi stakeholder; menyediakan layanan digital banking; access channel yang luas dilengkapi dengan fitur yang lengkap dan terintegrasi; menyesuaikan leading edge IT trend; digitalisasi, automasi, dan simplifikasi proses; membangun kolaborasi dan sinergi berbagai ekosistem; serta adanya layanan e-channel 24 jam.

Digitalisasi produk dapat dilakukan dengan inovasi dan pengembangan secara menyeluruh terhadap produk perbankan secara digital sehingga mampu memberikan pelayanan secara optimal kepada nasabah dan masyarakat, antara lain pengajuan kredit online, penyempurnaan credit approval system, dan penyempurnaan credit scoring system. Dalam hal pemasaran digital, upaya menaikkan pangsa pasar dengan memanfatkan media sosial seperti YouTube, Instagram, Twitter, Facebook, dan media elektronik lainnya. 
Peningkatan layanan customer dapat dilakukan dengan memberikan pelayanan kepada nasabah melalui peningkatan fitur mobile banking dan internet banking, khususnya payment, serta penyediaan customer online on boarding dilengkapi fitur yang jauh lebih lengkap seperti desain tampilan yang interaktif, profil pemegang rekening, multiple account, cardless ATM/CRM, dan lain-lain

Langkah berikutnya, interkoneksi dengan memanfaatkan API (open banking) sebuah konsep dalam layanan keuangan berdasarkan beberapa prinsip: penggunaan API terbuka yang memungkinkan pengembang pihak ketiga untuk membangun aplikasi dan layanan di sekitar lembaga keuangan, meningkatkan opsi transparansi keuangan bagi pemegang rekening dan penggunaan teknologi untuk mencapai prinsip-prinsip tersebut. Langkah lainnya adalah pengembangan TI dan memperbanyak sinergi ekosistem dengan berkolaborasi bersama perbankan/fintech, peluang baru melalui digitalisasi payment (e-ticketing, e-commerce, e-government) serta peningkatan limit transaksi melalui $e$-channel.

\section{Peningkatan Kualitas SDM}

Manajemen sumber daya manusia memainkan peran penting dalam membangun fondasi untuk keunggulan kompetitif (Offstein et al., 2005). Ini dimaksudkan bahwa PT Bank X harus memiliki sumber daya manusia yang mumpuni dengan bekerja sama pada lembaga pendidikan atau pelatihan sehingga karyawan dapat memberikan kontribusi positif kepada organisasi meliputi pengetahuan, skill, dan perilaku (knowledge, skill, attitude) sesuai dengan kebutuhan bank. Hal ini bertujuan untuk membangun konsep link and match dalam pengembangan sumber daya manusia yang memiliki daya saing tinggi sebagai upaya peningkatan bisnis.

Strategi pertama adalah menjalankan prinsip segregation of duty untuk mencegah adanya personil yang dapat melakukan kesalahan atau pelanggaran, baik disengaja ataupun tidak disengaja, tanpa diketahui atau tanpa terdeteksi. Kedua, PT Bank X dapat menempatkan personil yang memiliki kemampuan dan keahlian yang sesuai dan dapat mendukung pelaksanaan fungsi-fungsi secara maksimal dan melakukan evaluasi kinerja secara berkala dengan mempertimbangkan kompetensi sumber daya manusia yang sesuai dengan posisi. Ketiga, sebagai BUMD Pemerintah Propinsi, PT Bank X dapat mempersiapkan jurus jitu yang lebih baik dibidang customer service, menggunakan pendekatan kultur budaya masyarakat sehingga personal touch-nya lebih bagus dengan market untuk mendukung manajemen kinerja yang efektif. Penting bagi PT Bank X untuk mempertimbangkan peningkatan keterampilan karyawan, pemikiran kritis, pemecahan masalah, pelatihan silang, penugasan yang challenging, adanya feedback secara fungsional antara manajer, rekan kerja, dan bawahan.

\section{Implikasi Manajerial}

Berdasarkan hasil analisis menggunakan balance score card dan analisis SWOT yang telah dilakukan, strategi pertumbuhan yang tepat untuk perbankan secara umum sesuai grow and build strategy adalah product development secara spesifik adalah melalui peningkatan kualitas SDM, perbaikan layanan kredit, serta digitalisasi perbankan dalam memersiapkan persaingan di era revolusi industri 4.0. Upaya menjaga kualitas kredit dapat dilakukan dengan mengoptimalkan sejumlah strategi, dimulai dari ketentuan persetujuan plafond kredit, menelaah mitigasi risiko yang lebih prudent serta langkah restrukturisasi kredit bermasalah. Langkah-langkah yang diambil menjadi kunci kesiapan perbankan dalam menghadapi kredit bermasalah kedepannya agar dengan mudah dalam menyelesaikan ketika terjadi kredit yang tidak diharapkan. Bank dapat membentuk Sub Divisi Pengembangan Digital Banking untuk merumuskan pengembangan produk dan layanan digital Bank serta IT Strategic Plan. Digitalisasi produk dapat dilakukan dengan inovasi dan pengembangan secara menyeluruh terhadap produk perbankan secara digital sehingga mampu memberikan pelayanan secara optimal kepada nasabah dan masyarakat dengan memberikan pelayanan kepada nasabah melalui peningkatan fitur mobile banking dan internet banking, interkoneksi dengan memanfaatkan API (open banking) untuk pengembangan TI dan memperbanyak sinergi ekosistem dengan berkolaborasi bersama perbankan/ fintech. Dalam upaya peningkatan kualitas SDM, beberapa strategi bisa dilakukan yaitu (1) menjalankan prinsip segregation of duty untuk mencegah adanya personil yang dapat melakukan kesalahan atau pelanggaran, (2) PT Bank X dapat menempatkan personil yang memiliki kemampuan dan keahlian yang sesuai dan dapat mendukung pelaksanaan fungsi-fungsi TI secara maksimal. (3), sebagai BUMD Pemerintah Propinsi, PT Bank X dapat memersiapkan jurus jitu yang lebih baik di 
bidang customer service, menggunakan pendekatan budaya masyarakat sehingga personal touch-nya lebih bagus.

\section{KESIMPULAN}

Hasil penelitian ini menunjukkan bahwa, kinerja pada perspektif keuangan menunjukkan hasil yang cukup baik bahkan terus mengalami perkembangan dari tahun 2017 hingga 2019 dan dapat mencapai cost effectiveness. Pada proses bisnis internal rata-rata keseluruhan Network Growth Ratio adalah sebesar $4 \%$ dan prosentase rata-rata AETR sebesar 30\%. Hal tersebut berpengaruh pada perspektif nasabah/ konsumen yang dapat mencapai rata-rata profitabilitas nasabah sebesar $42 \%$ serta perolehan prosentase nasabah sebesar 9\% serta pada tingkat mempertahankan nasabah sebesar $91 \%$ yang mengidentifikasi hasil tersebut termasuk dalam kategori very good. Dari perspektif nasabah, menunjukkan nilai rata-rata yang diperoleh dari profitabilitas nasabah yang menyentuh angka sebesar $42 \%$. Hal ini menandakan semakin tinggi profitabilitas maka semakin tinggi perolehan laba yang berhasil diraih oleh perusahaan. Kinerja perspektif pertumbuhan dan pembelajaran perusahaan mengalami penurunan selama periode tahun 2017 hingga tahun 2019, dengan rata-rata sebesar 62\% lebih rendah $1 \%$ jika dibandingkan dengan prosentase pelatihan karyawan pada tahun 2017, hal ini memengaruhi tingkat produktivitas karyawan yang juga mengalami penurunan selama periode tiga tahun berjalan. Strategi pertumbuhan yang tepat sesuai grow and build strategy adalah product development secara spesifik adalah melalui peningkatan kualitas SDM, perbaikan layanan kredit, serta digitalisasi perbankan dalam memersiapkan persaingan di era revolusi industri 4.0.

\section{DAFTAR PUSTAKA}

Beneda, N. (2008). Wealth preservation through effective competitive strategy. Corporate Finance Review. 13 (1), 41-6.

Bostan, I., \& Grosu, V. (2011). Contribution Of Balance Scorecard Model In Efficiency Of Managerial Control. Romanian Journal Of Economic Forecasting, 3(22), 178-199.

Cassidy, C. M., Glissmeyer, M. D., \& Capps, C. J. (2013). Mapping An Internal-External (I-E) Matrix Using Traditional And Extended Matrix Concepts. Journal Of Applied Business Research, 29(5), $1523-1528$.

Gurel, E. (2017). SWOT Analysis: A Theoretical Review. The Journal Of International Social Research. 37(1), 1-27.

Ika, L. A., Diallo, A., \& Thuillier, D. (2012). Critical Success Factors For World Bank Projects: An Empirical Investigation. International Journal Of Project Management, 30(1), 105-116. Https://Doi.Org/10.1016/J.Ijproman.2011.03.005

Kairu, E. W., Wafula, M. O., Okaka, O., Odera, O., \& Kayode, E. (2013). Effects of Balanced Scorecard on Performance of Firms in the Service Sector. European Journal Of Business And Management, $5(9), 81-89$.

Kaplan, Robert S., and David Norton. (1992). "The Balanced Scorecard: Measures that Drive Performance." Harvard Business Review 70, no. 1 (January-February 1992): 71-79.

Kaplan, R. S., \& Norton, D. P. (1996). Using the balanced scorecard as a strategic management system.Harvard Business review.74 No 1. January-February 1996. 1-13.

Liang, T. P., You, J. J., \& Liu, C. C. (2010). A Resource-Based Perspective on Information Technology and Firm Performance: A Meta Analysis. Industrial Management And Data Systems, 110(8), $1138-1158$. 
Kukuh Wahyudi, Nimas Aryany Pratiwi, \& Maria Eliza. Penerapan Balanced Scorecard serta Analisis SWOT dalam Perancangan Strategi pada Badan Usaha Milik Daerah PT Bank X

Messai, A. S., \& Jouini, F. (2013). Micro and Macro Determinants of Non-Performing Loans. International Journal Of Economics And Financial Issues, 3(4), 852-860.

Najjar, S. Al, \& Kalaf, K. H. (2012). Designing A Balanced Scorecard To Measure A Bank' S Performance : A Case Study. International journal of business administration, 3(4), 44-53.

Namugenyi, C., Nimmagadda, S. L., \& Reiners, T. (2019). Design of A SWOT Analysis Model and Its Evaluation In Diverse Digital Business Ecosystem Contexts. Procedia Computer Science, 159, $1145-1154$.

Offstein, E. H., Gnyawali, D. R., \& Cobb, A. T. (2005). A Strategic Human Resource Perspective Of Firm Competitive Behavior. Human Resource Management Review, 15(4), 305-318.

Olson, E. M., \& Slater, S. F. (2002). The balanced scorecard, competitive strategy, and performance. Business Horizons, 45(3), 11-16.

Ozili, P. K. (2019). Non-Performing Loans And Financial Development: New Evidence. Journal Of Risk Finance, 20(1), 59-81. Https://Doi.Org/10.1108/Jrf-07-2017-0112

Peraturan Otoritas Jasa Keuangan Nomor 42/POJK.03/2017 Tahun 2017. (online). https://peraturan.bpk.go.id/Home/Details/129664/peraturan-ojk-no-42pojk032017-tahun-2017, diakses pada 8 Maret 2021.

Peraturan Otoritas Jasa Keuangan Nomor 12 /POJK.03/2018 Tahun 2018. (online). https://peraturan.bpk.go.id/Home/Details/128612/peraturan-ojk-no-12-pojk032018-tahun-2018, diakses pada 12 Maret 2021

Rafiq, M., Zhang, X. P., Yuan, J., Naz, S., \& Maqbool, S. (2020). Impact Of A Balanced Scorecard As A Strategic Management System Tool To Improve Sustainable Development: Measuring The Mediation of Organizational Performance Through PLS-Smart. Sustainability (Switzerland), 12(4), 1-19.

Ritson, N. (2008). Strategic Management, Bookboon: Neil Ritson \& Ventus Publishing ApS.

Rostami, M., Goudarzi, A., \& Zaj, M. M. (2015). Defining Balanced Scorecard Aspects In Banking Industry Using Fahp Approach. International Journal Of Economics And Business Administration, 1(1), 25-38.

Srivastava, M., Franklin, A., \& Martinette, L. (2013). Building a sustainable competitive advantage. Journal of technology management \& innovation, 8(2), 47-60.

Svitalkova, Z. (2014). Comparison And Evaluation Of Bank Efficiency In Selected Countries in EU. Procedia Economics And Finance, 12(March), 644-653.

Talebnia, G. (2012). The Major Perspectives Weighted Model For Balanced Scorecard System In The Case Of Auto Industries. Indian Journal Of Science And Technology, 5(10), 3412-3420.

Tuan, T. T. (2020). The Impact of Balanced Scorecard on Performance: The Case of Vietnamese Commercial Banks. Journal Of Asian Finance, Economics And Business, 7(1), 71-79.

Varadarajan, P., \& Berry, L. L. (1983). Strategies for Growth in Banking: An Exposition. International Journal Of Bank Marketing.1(1). 15-25.

Velimirović, D., Velimirović, M., \& Stanković, R. (2011). Role and importance of key performance indicators measurement. Serbian Journal of Management, 6(1), 63-72. 
Wu, H. Y. (2012). Constructing A Strategy Map For Banking Institutions With Key Performance Indicators Of The Balanced Scorecard. Evaluation And Program Planning, 35(3), 303-320.

\section{Lampiran 1. DIAGRAM ALUR SWOT}

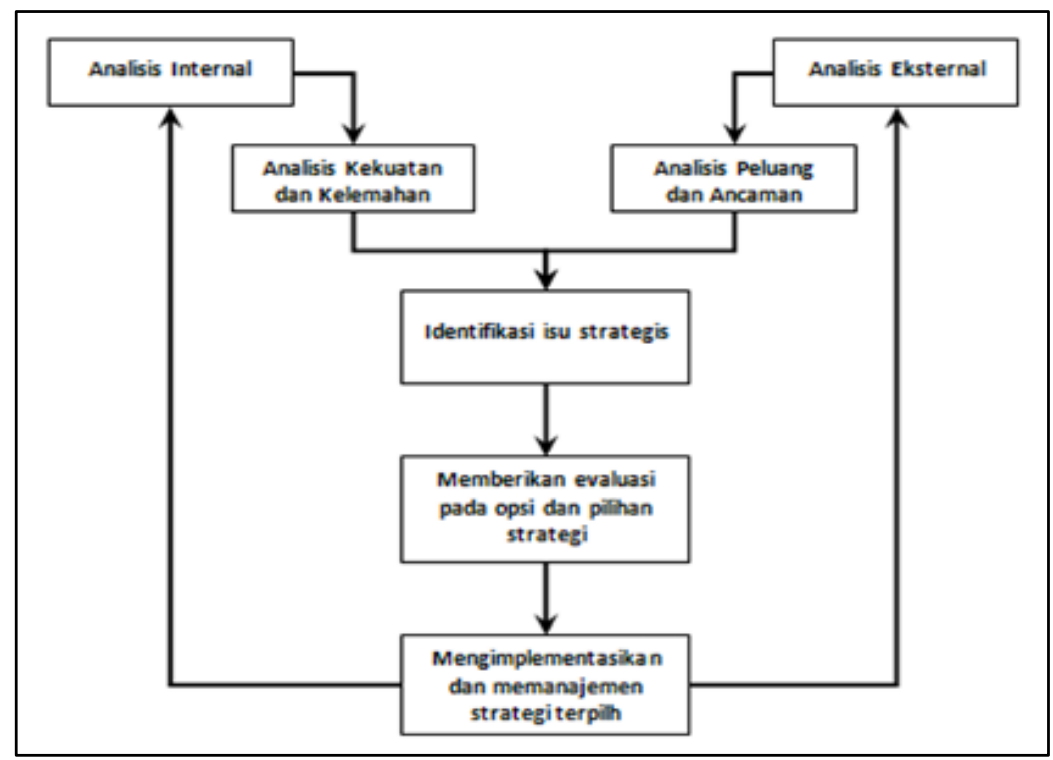

Sumber: Ritson (2008)

\section{Lampiran 2. ANALISA SWOT PT BANK X}

\section{STRENGTHS}

- Rasio keuangan yang cukup sehat sesuai kriteria Bank Indonesia

- Jaringan pelayanan yang cukup luas pada propinsi tersebut

- Sumber dana yang dikelola relatif murah, didominasi oleh pemerintah

- Retensi karyawan sangat kecil

- Hubungan kelembagaan yang baik termasuuk lembaga pemerintah dan swasta

\section{OPPORTUNITIES}

- APBD setiap tahun dipastikan meningkat, memberikan peluang bagi PT Bank X untuk meningkatkan ekspansi kredit

- Relasi yang baik dengan pemerintah propinsi

- Menangani kelompok usaha skala kecil, PAD dan dana perimbangan

- Kebijakan uang ketat dengan operasi pasar terbuka sesuai instrumen SBI

- Penggunaan Internet of Things yang meningkat

Sumber: Data diolah (2021)

\section{WEAKNESSES}

- Product Development kurang inovatif

- Aktivitas pemasaran relatif kurang agresif

- Corporate Image masih sangat kental sebagai bank daerah

- Teknologi sistem informasi perlu disempurnakan

\section{THREATS}

- Produk pesaing semakin inovatif dan menarik

- Banyaknya pemain baru dalam industri jasa keuangan

- Financial technology berkembang cukup pesat 